\title{
Development of a "Survival" Guide for Substance Users in Harlem, New York City
}

\author{
Stephanie H. Factor, MD, MPH \\ Sandro Galea, MD, MPH \\ Lucia Garcia de Duenas Geli, BPharm, MPH \\ Megan Saynisch, BA \\ Suzannah Blumenthal, BA \\ Eric Canales \\ Michael Poulson, MPH \\ Mary Foley, EdD \\ David Vlahov, $\mathrm{PhD}$
}

\begin{abstract}
The community advisory board (CAB) of the Harlem Urban Research Center, which includes community service providers, Department of Health workers, and academics, identified substance users' health as an action priority. The $\mathrm{CAB}$ initiated the development of a wellness guide to provide informational support for substance users to improve access to community services. Focus groups of current and former users engaged substance users in the guide development process and determined the guide's content and "look." Focus group participants recommended calling this a "survival" guide. The guide will include three sections: (a) health information and how to navigate the system to obtain services, (b) a reference list of community services, and (c) relevant "hotline" numbers. The design will incorporate local street art. Substance users continue to shape the guide through ongoing art workshops. Dissemination and evaluation of the guide will continue to involve substance users, community service providers, and academics.
\end{abstract}

Substance use is a major public health problem in the communities of East and Central Harlem. The prevalence of opiate dependence in Harlem is 18 times the national average. ${ }^{1}$

Stephanie H. Factor, Center for Urban Epidemiologic Studies, New York Academy of Medicine, New York; Division of Preventive and Analytic Methods, Epidemiology Program Office, Centers for Disease Control and Prevention, Atlanta, Georgia. Sandro Galea, Center for Urban Epidemiologic Studies, New York Academy of Medicine, New York; Division of Epidemiology, Columbia University Mailman School of Public Health, New York. Lucia Garcia de Duenas Geli, Center for Urban Epidemiologic Studies, New York Academy of Medicine, New York; and National School of Health, Health Institute Carlos III, Madrid, Spain. Megan Saynisch, Center for Urban Epidemiologic Studies, New York Academy of Medicine, New York. Suzannah Blumenthal, Urban Public Health Program, Hunter College of the City of New York, New York. Eric Canales, Center for Urban Epidemiologic Studies, New York Academy of Medicine, New York; Community Advisory Board, Center for Urban Epidemiologic Studies, New York Academy of Medicine, New York. Michael Poulson, Community Advisory Board, Center for Urban Epidemiologic Studies, New York Academy of Medicine, New York; ACCESS Harlem, New York. Mary Foley, Community Advisory Board, Center for Urban Epidemiologic Studies, New York Academy of Medicine, New York; Department of Community Medicine, Mount Sinai School of Medicine, New York. David Vlahov, Center for Urban Epidemiologic Studies, New York Academy of Medicine, New York; Division of Epidemiology, Columbia University Mailman School of Public Health, New York.

Health Education \& Behavior, Vol. 29 (3): 312-325 (June 2002)

(C) 2002 by SOPHE

312 
Substance use alone is a poor health outcome and is a precursor to other poor health outcomes, including AIDS and hepatitis B and C infections. A substantial proportion of excess risk of death in Harlem has been attributed to cirrhosis and substance use. ${ }^{2}$

The Urban Research Center (URC) in Harlem is funded by a Centers for Disease Control and Prevention (CDC) cooperative agreement with the Center for Urban Epidemiologic Studies (CUES) at the New York Academy of Medicine (NYAM) and was started to study and improve social factors affecting the health of substance users in Harlem using a community-based participatory research (CBPR) approach. CUES conducts both qualitative and quantitative research in a variety of disciplines, including epidemiology, medicine, and sociology, to identify risk factors and effective interventions for the prevention and/or treatment of diseases commonly encountered in the urban environment.

\section{DEVELOPING PRIORITIES FOR ACTION}

The URC in Harlem was designed to facilitate CBPR. In CBPR, researchers partner with community persons for all stages of research, including intervention design and analysis. ${ }^{3}$ This community-academic partnership was formalized at the URC by the formation of a community advisory board (CAB) composed of community service providers, the New York City Department of Health (NYC DOH), and persons from academia. The $\mathrm{CAB}$ was to work with CUES staff members in directing and participating in URC research. Early meetings of the $\mathrm{CAB}$ identified substance use as a specific concern in the Harlem community. Previous studies have shown the success of community-academic partnerships for substance use research. ${ }^{4,5}$

The process through which substance use was identified as a priority for action is described elsewhere. ${ }^{6}$ Given the initial substance use focus, early CAB members, in collaboration with CUES staff members, invited additional persons who worked for community agencies, NYC DOH, and local academic institutions to join a board designed to make it easier to get treatment for substance use than to get substances in Harlem. ${ }^{7}$ The $\mathrm{CAB}$ evolved to include board members from most types of community organizations that provide services to substance users, including substance use treatment (including drug detoxification, methadone maintenance, and 12-step programs), housing, job training and placement, medical care (including primary care, HIV/AIDS treatment, and hepatitis awareness and treatment), and mental health care (Table 1). Efforts were made to include those who had had personal experiences with the problems faced by substance users; approximately one-third of current $\mathrm{CAB}$ members are former substance users in recovery. To ensure the inclusion of expertise in the broad range of issues that affect substance users, the board also includes members who work with vulnerable populations, including workers for domestic violence services and shelters for undocumented aliens.

$\mathrm{CAB}$ members approached the improvement of the health of substance users in two ways. First, $\mathrm{CAB}$ members and researchers designed a conceptual model for research and

Address reprint requests to Stephanie H. Factor, Center for Urban Epidemiologic Studies, New York Academy of Medicine, 1216 Fifth Avenue, Room 556, New York, NY 10029-5293; phone: (212) 822-7389; fax: (212) 876-6220; e-mail: sfactor@ nyam.org.

The authors thank all members of the Urban Research Center Community Advisory Board who have contributed to data collection and who have provided helpful feedback about the article. This work was partly funded by a Centers for Disease Control and Prevention Urban Research Centers Grant U48/CCU209663-07. 
Table 1. Organizations Represented on the Community Advisory Board of the Urban Research Center in Harlem, New York City

\begin{tabular}{|c|c|}
\hline Organization & Services Provided \\
\hline \multicolumn{2}{|l|}{ Hunter College } \\
\hline \multicolumn{2}{|l|}{ Legal Aid Commission Law Offices } \\
\hline \multicolumn{2}{|l|}{ Metropolitan Hospital } \\
\hline \multicolumn{2}{|l|}{ Mount Sinai Hospital } \\
\hline \multicolumn{2}{|l|}{ Mount Sinai School of Medicine } \\
\hline \multicolumn{2}{|l|}{ New York City Department of Health } \\
\hline \multicolumn{2}{|l|}{ North General Hospital } \\
\hline \multicolumn{2}{|l|}{ Community agencies } \\
\hline Association to Benefit Children & Job training and job placement services \\
\hline $\begin{array}{l}\text { East Harlem Community Health } \\
\text { Committee }\end{array}$ & $\begin{array}{l}\text { Coalition of East Harlem agencies concerned } \\
\text { with health policy }\end{array}$ \\
\hline Central Harlem HIV Care Network & $\begin{array}{l}\text { Coalition of organizations providing HIV/AIDS- } \\
\text { related services }\end{array}$ \\
\hline East Harlem HIV Care Network & $\begin{array}{l}\text { Coalition of organizations providing HIV/AIDS- } \\
\text { related services }\end{array}$ \\
\hline Harlem East Life Plan & $\begin{array}{l}\text { Methadone maintenance center with primary care } \\
\text { clinic }\end{array}$ \\
\hline $\begin{array}{l}\text { Harlem United Community AIDS } \\
\text { Center, Inc. }\end{array}$ & Day treatment center for persons with AIDS \\
\hline Latino Organization for Liver Awareness & Education about liver disease \\
\hline $\begin{array}{l}\text { Little Sisters of the Assumption Family } \\
\text { Health Service }\end{array}$ & $\begin{array}{l}\text { Substance abuse treatment and case management } \\
\text { for homeless persons }\end{array}$ \\
\hline Mount Sinai Health Bridge & Medical care for homeless people with AIDS \\
\hline $\begin{array}{l}\text { Mount Sinai Institute for Medicare } \\
\text { Practice }\end{array}$ & Studies effectiveness of Medicare policy \\
\hline Project Create & Variety of drug treatment programs \\
\hline Project Return & Variety of drug treatment programs \\
\hline The Riverside Church & $\begin{array}{l}\text { Food Pantry, Day Care Center, Senior Center, } \\
\text { Job training }\end{array}$ \\
\hline Settlement Health & Community-based clinic \\
\hline STEPS to End Family Violence & Domestic-violence services \\
\hline Veritas Therapeutic Community Inc. & Variety of drug treatment programs \\
\hline Women's Information Network & $\begin{array}{l}\text { Educational outreach about HIV and AIDS for } \\
\text { female sex workers }\end{array}$ \\
\hline
\end{tabular}

interventions. This model describes the role of social determinants in shaping health. Briefly, this model proposes that social factors such as social support, access to services, and discrimination can increase or decrease stress, which then affects personal risk behaviors, and which then affects health outcomes. Fundamental factors of money, prestige, and power directly and indirectly affect social factors, personal risk factors, and health outcomes. ${ }^{6}$

Second, CAB members discussed their experiences and concerns relevant to making it easier to access substance use treatment than to access substances. A number of problems, including limited access to services, were identified that could be contributing to poor health among substance users. ${ }^{6} \mathrm{CAB}$ members noted that substance use treatment was easy to get when a substance user was at a community organization (e.g., a health 
clinic or a domestic-violence center) and the person providing the service had personal "connections" with someone at an appropriate substance use treatment center. CAB members felt that these connections were formed when service providers had worked together in the past either on community boards or as colleagues at work. Thus, these connections were personal and frequently were lost when individuals left organizations. The rapid turnover of community service agency personnel caused frequent loss of these important connections.

Discussions regarding the nature of these connections was iterative, evolving in formal discussions at $\mathrm{CAB}$ meetings and in less formal discussions between $\mathrm{CAB}$ members outside of meetings. $\mathrm{CAB}$ members decided to design an intervention that would institutionalize these connections so that they would remain after the specific community service providers had left their jobs. CAB members felt that these connections fundamentally provided information such as knowing the name of the right person to call, who would admit patients without Medicaid, and who would admit patients during off-hours. Members therefore felt that the way to preserve these connections was to provide this kind of detailed information to all community service providers in Harlem. All community service providers would then know the name of the intake person at each substance use treatment facility, which substance use treatment center did not require Medicaid, and which programs would admit persons at off-hours. CAB members then proposed that such a guide be provided to all service providers and substance users in Harlem.

\section{A WELLNESS GUIDE}

The CAB felt that a guide, updated regularly by CUES staff workers in consultation with community agency staff members, might offer a solution to the problem of high staff turnover at community agencies and turnover of the agencies themselves. CAB members and CUES staff persons worked together over time to address the health of substance users; $\mathrm{CAB}$ members and CUES staff members would work together over time to regularly update the guide. The guide would be substantially different from a static "brochure" listing available services. The guide would be an evolving record of specific names and insider details about service agencies in Harlem. The connections made by the guide would be a product of the ongoing relationship between community partners and institutional investigators.

The idea of an ongoing writing and rewriting of a guide as part of the long-term partnership between community members and CUES investigators coincided with the development of the conceptual model of social determinants of health. ${ }^{6} \mathrm{CAB}$ members proposed that the guide would provide action to improve one form of social support. Specifically, the guide would improve "informational social support," which would then improve access to services. The guide would thus address one facet of community need.

Although initially conceived as a guide for service providers who would come into contact with substance users, board members felt that the way to improve social support was to develop the guide for substance users themselves. They felt that providing substance users with connections to treatment services would truly make access to substance use treatment easier for substance users. In addition, it was believed that involving substance users as partners in guide development would also provide an opportunity to build social support among participating substance users.

Researchers at CUES were familiar with a guide that had been written to provide informational social support for residents of California, titled the Wellness Guide. ${ }^{8}$ This guide 
provides informational social support for a variety of types of services. It was proposed that a Harlem guide be modeled on the Wellness Guide and, like the Wellness Guide, provide informational social support about a variety of services for substance users.

\section{THE WELLNESS GUIDE}

The Wellness Guide, ${ }^{8}$ coordinated by the University of California, Berkeley, was developed for all residents of California. The centerpiece of the project was an 80-page illustrated booklet detailing how to stay well and where to find help. It covered a range of personal, social, and environmental topics (including medical care, vaccinations, elder care, pregnancy, infant feeding, food assistance, housing, and family violence). The topics and advice were formulated in close collaboration with a range of California's residents during a 3-year period. Drafts were reviewed by approximately 500 persons and by specialists in 40 health-related areas. A Spanish-language version was also prepared. Both versions of the Wellness Guide were designed for readers with a primary school education. Attention was given to those with limited means and access to services. A telephonebased referral system was created to link the Wellness Guide with listings in phone directories throughout the state.

To evaluate the Wellness Guide, 100,000 copies were distributed through the state's women, infants, and children (WIC) nutritional supplement program. A total of 24 WIC clinics distributed the Wellness Guide; 12 comparison clinics did not distribute the Wellness Guide. A random sample of women from each clinic were interviewed 1 to 2,2 to 4, and 6 to 8 months after the Wellness Guide was distributed. Results documented that differences in knowledge, confidence in knowledge, and individual sense of control consistently favored recipients of the Wellness Guide. ${ }^{9}$

$\mathrm{CAB}$ members felt that a guide modeled after the Wellness Guide would be helpful to substance users in Harlem. CAB members and researchers agreed on a plan for development of the guide: Substance users would determine the content and appearance of the guide, researchers at CUES would work with engaged substance users in adapting this content, a graphic artist would design the guide based on user recommendations, and all board members would review the work at monthly intervals.

\section{DEVELOPMENT OF A WELLNESS GUIDE IN COLLABORATION WITH SUBSTANCE USERS}

$\mathrm{CAB}$ members and CUES researchers wanted a guide that was relevant and current. Although several former substance users participate in the CAB, it was felt that many more substance users had to be actively involved in guide development to ensure the relevance of the material. Although substance users are frequently the subject of research and intervention, they are less frequently involved in the development and implementation of interventions designed for them. Studies have demonstrated that substance users are motivated to participate in research and interventions designed to benefit other substance users. A recent survey showed that drug users' motivation for participation in research includes altruism, seeking information or assistance, and personal satisfaction. ${ }^{10}$ Altruism was a prominent feature of substance users' willingness to participate in research trials for experimental vaccines. ${ }^{11,12}$ This evidence, coupled with $\mathrm{CAB}$ members' and inves- 
tigators' experience, suggested that involving substance users in guide development was feasible.

$\mathrm{CAB}$ members and researchers developed a plan to include the opinions of many substance users to make sure the content of the guide was relevant. Data collected to determine the relevant content included quantitative data from structured interviews with individual users and qualitative data obtained from focus groups of users. The quantitative data from the interviews identified topics most important to substance users and are described elsewhere. ${ }^{6}$

The focus groups served several purposes. Users were encouraged to present their own ideas and to build on the ideas of others about what to include in the guide. Focus groups were also used to determine how users could become even more involved in the process of developing and implementing the guide.

The initial plan to make sure the content of the guide remained current included input from two sources. $\mathrm{CAB}$ members felt that the active relationship between CUES staff persons and $\mathrm{CAB}$ members would provide one way of keeping the guide current. CUES staff members had access to substance users who could provide ongoing evaluation of the guide. Specifically, CUES conducts cohort studies among substance users to identify risk factors for HIV, hepatitis B and C, and TB infection. Participants in the cohorts are interviewed at 2-month intervals at a Harlem storefront site. In addition, individual substance users and focus groups of substance users are recruited to this site when input from substance users is needed. Evaluations of the first version of the guide and subsequent revisions were to be done at the storefront using individuals from both ongoing studies and asneeded recruitment.

\section{FOCUS GROUPS}

Four focus groups were convened with clients from $\mathrm{CAB}$ member agencies during the summer and fall of 2000. The five $\mathrm{CAB}$ member agencies that participated in this research all serve current and/or former substance users. The four focus groups included the following:

1. Active users from Settlement Health's active user support group and former users from Project Create's outpatient substance use treatment program.

2. Former users from North General Hospital Outreach Program - an outpatient treatment program for substance users.

3. Former users from Women in Crisis, Project Return Foundation, Inc. who participate in their outpatient substance abuse treatment program.

4. Current and former users from Harlem-Dowling West Side Center's support group for people infected with HIV.

The four focus groups were facilitated and analyzed by a $\mathrm{CAB}$ member trained in focus group methodology and by one other facilitator. The second facilitator was either another $\mathrm{CAB}$ member, the CUES special projects coordinator, or an intern from Hunter College Graduate School. Participants were reimbursed $\$ 20$ for their time and were offered refreshments and free transportation. The groups lasted 1 to 2 hours. Groups were recorded via audiotape to ensure that information was obtained and recorded accurately. For confidentiality, the focus group participants provided no identifying information 
about themselves (i.e., name, social security number, and address). The tapes will be destroyed following completion of the project. Selected persons were asked to elaborate on their responses in a one-on-one interview after the group concluded. Finally, the second facilitators were interviewed immediately after the groups concluded to gauge their impressions of this process (debriefing).

The following focus group questions were developed through discussions with the CUES staff, CAB members, and participants at the CUES Substance Abuse Symposium planning meeting held in the fall of 2000. These questions were designed to stimulate discussion around general themes:

1. Do you think a "wellness" guide would be useful in this community?

2. If not, what would be useful?

3. If so, what types of information should be included?

4. How much information should this guide provide?

5. How much detail should be included?

6. What size, shape, color, language, and reading level should be used?

7. What would a page of this guide look like?

The focus groups served as the data collection method for the questions listed above. ${ }^{13}$ Data from the focus groups were analyzed using content analysis. ${ }^{14,15}$ The themes that evolved from the early $\mathrm{CAB}$ discussions were used for this analysis. The predetermined themes were the following: role of a wellness guide, content of the guide, and format and appearance of the guide. Audiotapes of interviews were transcribed into Microsoft Word files. Analysis included reading the files and copying and pasting related responses into a master file. Data were first placed into predetermined themes by one of the investigators. A second investigator reviewed the data and determined if she agreed with the initial placement of data into thematic categories. Both investigators reviewed and reconciled differences in data analysis. This master file was then read repeatedly to obtain data from the focus groups about the predetermined themes. The Institutional Review Boards of Columbia University and the CDC reviewed this protocol.

\section{SUMMARY OF FOCUS GROUP RESULTS}

All participants were adults (age 24-63), former or present substance users, with multiple substance use treatment episodes. Of the 29 participants, 15 were female and 14 were male. There were 16 African American, 12 Hispanic, and 1 Asian participant(s). This group is representative of substance users in this community in age, sex, and race/ ethnicity. ${ }^{16}$ Representative quotes regarding each theme are presented in Table 2.

\section{GUIDE CONTENT AND FORMAT}

Participants favored the idea of a "survival" guide (Table 2). To address the needs outlined by the participants in the focus groups, $\mathrm{CAB}$ members and researchers developed an outline for the survival guide content. In response to participants' emphasis on the need for information about where and how to access health and social services (Table 2), the 
first section will include information about health and how to navigate through the system to obtain services. The health information will include general health issues (including cancer and diabetes screening, nutrition, and dental care) and health issues relevant to substance users (such as safe injection practices). Figure 1 is an example of one of these issues. This section will also include information about how to navigate through the system by describing how to get important documents (e.g., identification cards), kinds of community services available (e.g., job opportunities for former substance users and previously incarcerated persons, needle-exchange programs, services for domestic violence), and the necessary steps to get community services (e.g., paperwork required, eligibility criteria, and whether one can walk in). In addition, this section will include information on how to prepare for jobs and job interviews, including résumé development.

To further address participants' need for practical information to better access services (Table 2), the second section will include a reference list of community services, including job services, education services, legal service, substance use treatment services, and medical services (including health clinic, mental health services, HIV services, and alternative treatment). On the basis of the quantitative data, ${ }^{6}$ housing services will also be included. There will be detailed information about each community service. In addition to the types of information presented in traditional resource guides like phone number, address, and hours of operation, the survival guide will include information to help substance users steer through the available services as informed consumers. For example, the survival guide will include the name of a specific contact person at the community service, how to get to the service by using public transportation, and the length of waiting time to get the service once the organization has been notified. This section will also include a map of available community services.

To provide participants with a wide range of services (Table 2), the third section will complement Section 2 by including relevant "hotline" numbers. These will include local, state, and national hotlines on services for substance use, mental health, HIV, hepatitis B, hepatitis $\mathrm{C}$, tuberculosis, and other topics covered in the survival guide.

To respond to substance users' desire for services with supportive environments (Table 2 ), these three sections will have testimonials from former substance users stating how comfortable they felt with the workers at these agencies. In response to participants' suggestions (Table 2), the guide will be pocket-size and include artwork that will make it vivid and appealing.

\section{ONGOING SUBSTANCE USER PARTICIPATION IN THE FOCUS GROUP PROCESS}

The focus groups extended the participatory action research process to include substance users. ${ }^{17}$ By acknowledging substance users' "expertise" in communicating with other substance users, users were identified as "experts" participating in a research process. By seeing themselves as experts in this research process, users identified other points in the process where their expertise would be necessary. After the initial focus group sessions, focus groups of substance users, including some initial participants and other interested users, continued to develop the survival guide. Using the outline developed from the initial focus groups, CAB members and CUES investigators wrote the first 
䜣 Table 2. Focus Group Results

\begin{tabular}{|c|c|c|}
\hline Theme & Quotes & Brief Interpretation \\
\hline \multirow[t]{2}{*}{ Role of a Wellness Guide } & $\begin{array}{l}\text { Dealing with substances is day to day. It's about } \\
\text { survival. . . Yeah, this should be a survival } \\
\text { guide. }\end{array}$ & Participants favored the idea of a "survival" guide. \\
\hline & You need help to do this. You can't do this alone. & $\begin{array}{l}\text { When asked if a guide designed to help users access services would be } \\
\text { helpful, they all agreed that it would be. Focus group participants also } \\
\text { mentioned other ideas about potential interventions that could assist } \\
\text { substance users. These ideas are being used to inform other work of } \\
\text { the Urban Research Center. }\end{array}$ \\
\hline \multirow[t]{2}{*}{ Content of the guide } & $\begin{array}{l}\text { [I need to] learn more about HIV, hepatitis C, } \\
\text { and TB. }\end{array}$ & $\begin{array}{l}\text { Participants wanted health information that is specifically applicable to } \\
\text { substance users and general information about healthy living. }\end{array}$ \\
\hline & $\begin{array}{l}\text { [The most difficult part of accessing services is] } \\
\text { keeping [or getting] ID. You can't get nothing } \\
\text { without a Medicaid card. They know you don't } \\
\text { have none [ID], but they won't let you in } \\
\text { without it. If you really want to help folks out, } \\
\text { figure out some way to get people in [for } \\
\text { substance treatment] for a day or two while }\end{array}$ & $\begin{array}{l}\text { Participants needed information to help them better access the services } \\
\text { they did know about. For example, they stressed the need to know } \\
\text { about how to get an identification (ID) card and how to go about } \\
\text { preparing to get a job. When participants referred to an ID card, they } \\
\text { were specifically referring to any kind of card that had their picture, } \\
\text { their name, and appeared legitimate; they needed some way to } \\
\text { demonstrate they were who they said they were. }\end{array}$ \\
\hline
\end{tabular}
their ID gets processed.

I need life skills, coping skills, individual therapy, and group counseling. I need to learn how not to be myself. I need mental health services [behavior modification] so I can learn how to act right . . . I also need some stress relief: some Shiatsu, or Reiki, or acupuncture.

[You] know I been clean for 6 months, and they're telling me I might not get her back! I need help to get my baby back.

Participants wanted information about medical services of all types.

Participants expressed the need for legal services. 
Format and appearance of the guide
I want the opportunity to make an honest living, so Par I can get my own place. ... We need some real jobs too, not just these ex-con security guard gigs.

[I need] help getting my GED [general equivalency diploma], help getting into vocational schools and unions.

I need a safe haven where I can talk to someone I can trust ... [I want to go to a place that has] workers you can trust. ... We need to be able to find a doctor that's not afraid to touch you. People's experiences should be talked about: testimonials, success stories. . . . [We] need to see somebody that's done this. We need to see success stories, folks that made it. . . . It should be inspirational. It should inspire you to do the right thing. . . . It should be spiritual, not religious. ... I got to believe in somethingthat something or someone can love me.

It should be small. ... You should be able to keep it with you at all times. . . . Addiction is with you at all times. You should carry this like I carry my Bible.

It should be eye-catching, attractive, goodlooking. ... Electric colors, fluorescent, bright like a neon sign. ... The outside could look like graffiti. Everyone grew up with graffiti. People can relate to it. ... [It needs] positive images that convey hope. Maybe a sunrise, a rainbow, or little figures scaling a mountain.

No sugar coating. This should be the real deal. rticipants expressed desires for a wide range of services. They wante information about job opportunities and educational opportunities.

Participants expressed the need for emotional support; they wanted to be referred to places that were warm and welcoming.

Participants felt that the guide required inspirational messages based on other people's success stories. They were interested in spirituality, not specifically in God.

Participants felt the survival guide should be pocket-size.

Participants felt it should be attractive with bold colors. 


\section{Safe Injection}

Sharing needles, syringes, cotton and cookers, and other parts of your works can spread HIV and Hepatitis.

$>$ You can also get sick from injecting on the wrong place on your body or getting pieces of cotton in your blood.

$>$ Injecting bad drugs or drugs laced with something can make you very sick or even kill you. Call 911 right away if you think this has happened to you (or a friend)!

Here is some information on injecting safely:

- Make Every Injection With A New, Sterile Syringe. Use a fresh set every time you shoot up. You can tell that a needle is new and sterile if the cap clicks when you turn it. Check out the info on New York City needle exchange programs on page 27.

- Never share your needle, syringe, cotton, cooker, or water with anyone, even people you know.

- Safer Places to Inject:

Inject the same way your blood flows.

$>$ Always inject into veins, not arteries. Veins are closer to the surface of your skin and their blood is a darker red.

If you hit an artery you will bleed very quickly-this is very dangerous.

$>$ If you do hit an artery, the blood will come out in spurts. Put direct pressure on the spot the blood is coming out of for at least 10 minutes to stop the bleeding.

$>$ If you inject into your groin, be careful--there is a major artery right next to the vein.

Do not inject into your neck. This is dangerous-infections can go to your brain.

- Try to clean your hands and the place on your body where you are going to inject with soap and warm water or an alcohol pad.

- Use a cotton that:

1. Is sterile (comes wrapped in its own package)

2. You don't have to break up to get to the right size

3. Doesn't have fibers that could break off

- Your tie/tourniquet should be:

1. Thick enough so that it won't hurt your skin when you pull it tight

2. Stretchy-this makes it easier to pull it tight and take it off

3. Able to be cleaned

- Put the cap back on your used syringes and put them in a container that won't let the needles stick through, like a soda or bleach bottle with a lid

- $\mathrm{OR}$ take your used syringes to a syringe exchange program to get new syringes.

Figure 1. Sample survival guide health information page.

draft of the survival guide. The subsequent focus groups have reviewed and modified both the content and format of the guide to make it more useful for users. Other important content areas have been identified through this ongoing process. For example, most of the participants were unaware of a new law permitting the purchase of syringes through pharmacies without a prescription. This information will be included in the guide. A Harlem artist was brought into the survival guide development process. He facilitated art workshops with substance users. In each workshop, users created drawings and paintings to illustrate the survival guide. Future focus groups will be held to obtain testimonials about services included in the guide.

The focus groups also provided users with a formal way of sharing their knowledge with other users. In this way, they provided informational social support to other users. It is hoped that the provision of informational social support will be ongoing- that the 
guide will be continually updated to provide the most current "informational social support" that users can give to each other.

\section{EVALUATION AND LONGER TERM UPDATING OF GUIDE}

The survival guide will be ready for printing in March 2002. We will conduct a "randomized, controlled trial" to evaluate the guide. A series of standardized questions will be asked of a cohort of users. We will ask questions regarding health-related knowledge and familiarity with services in the community. A randomly selected sample of this cohort will receive the survival guide. We will then reinterview the entire cohort 2 and 6 months later to evaluate the effectiveness of the guide in improving knowledge and access to services. We will also ask questions about guide content and format at the 2- and 6-month evaluations to help guide subsequent revisions. After formal evaluation and possible modification, we will distribute the guide throughout the Harlem community. Service providers and substance users will provide their expertise in distributing the guide.

The survival guide will be updated continually. Substance users who have participated in the focus groups outlined here will be invited to participate in future periodic focus groups to review the survival guide to determine its relevance and to keep it current. Other interested substance users will also be included. It is hoped that substance users will help determine how often these periodic reviews should occur. In addition to focus groups with substance users, the $\mathrm{CAB}$ survival guide subcommittee will elicit feedback from $\mathrm{CAB}$ members at the regular monthly meetings. Substance users involved in storefront studies will provide feedback both formally in standardized questionnaires and informal conversations in the storefront waiting area. The CAB survival guide subcommittee will review all these data quarterly. The guide will be reprinted when needed. Future dissemination also will require service provider and substance user expertise.

\section{DISCUSSION}

We have described a participatory process in which a survival guide for substance users was identified as an action priority and substance users participated in its development. Substance users are now involved in all aspects of guide development. The guide will be a "survival" guide rather than a "wellness" guide. The content of the guide will include how to stay healthy and navigate the system, helpful resources in the community, and relevant hotline numbers. The guide will be an easy-to-read, forthright, pocket-size "survival guide" with bold colors, graffiti designs, and work of local artists. Substance users were enthusiastic about the proposed guide and eager to participate beyond the scope of the initial focus groups. Users have subsequently provided artwork and are continuing to provide contents and evaluations of contents for the guide.

This process extended participatory action research to include substance users. Through the focus groups, substance users produced knowledge for other substance users. Also through the focus groups, substance users determined how that knowledge would be used to help other substance users. Thus, through the focus groups, substance users have retained ownership of their knowledge. By participating in each part of the process that uses substance user expertise and is meant for substance users, substance users have participated in participatory action research. 
This process has current limitations and future challenges. Although the focus group members were representative of the substance users in Harlem in terms of race and gender, participants were selected because of their association with an agency. We do not know if they are representative of users not associated with agencies. Users not currently associated with agencies may be most in need of help. The importance of this guide is based on a model of social determinants that suggests that the provision of informational social support will improve substance users' ability to access services. It is possible that the model does not accurately represent the role of social factors. It is also possible that the model may be applicable to certain populations and not to others. Published reports have demonstrated the need for informational support both among patients in hospitals ${ }^{18}$ and among relatives of patients. ${ }^{19}$ Informational social support in the form of prenatal classes has been shown to be associated with expectant mothers' mental well-being. ${ }^{20}$ It is possible that substance users as a group are not helped by these types of interventions. It is also possible that some social factors and/or personal factors are helped by informational social support and others are not. For example, it is possible that informational social support cannot improve access to services. A process to keep the guide current has been proposed, but this task is a challenge for the future and will require collaboration between substance users, CAB members, and CUES staff persons.

The process of guide development was part of a broader set of NYC URC activities. The $\mathrm{CAB}$, through a series of discussions, decided that implementation of a guide was a critical first activity for the NYC URC. The guide was designed to provide ongoing links between substance users and necessary social services. The focus groups determined the role, content, and look of the guide and provided the means for substance users to further expand their role in creating a useful product for their community. Work on the guide was started in parallel with other work designed to erase barriers to access faced by substance users in Harlem. The guide was not intended as the sole solution to limited social support among substance users. The guide only addresses a few aspects of the social determinants of health; other social determinants of health need to be addressed by other projects. The development of the survival guide is an appropriate and achievable first step.

\section{IMPLICATIONS FOR PRACTICE}

In choosing to develop a guide that can improve substance users' access to services, the $\mathrm{CAB}$ has partnered with current and former substance users to design and eventually distribute a survival guide. Through this process, current and former users have moved beyond being study "participants" into active partners who shape the development process. Substance users are nontraditional partners in research and interventions. This partnership has improved the quality of the development process. Substance use has been an area of public health concern and public policy debate. Our experience suggests that substance users can be partners in both public health and public policy projects.

This intervention is a small effort that addresses only one aspect of the many factors that affect the health of substance users. Focus group participants identified many other potential interventions that may also improve the health of substance users. These ideas are contributing to other URC activities. The development process for the survival guide has built strong partnerships between substance users, $\mathrm{CAB}$ members, and researchers that will enhance future research and interventions. 


\section{References}

1. Fullilove RE, Fullilove MT, Northridge ME, Ganz ML, Bassett MT, McLean DE, Aidala SS, Gemson DH, McCord C: Risk factors for excess mortality in Harlem: Findings from the Harlem Household Survey. Am J Prev Med 16:22-28, 1999.

2. Wallace R, Fullilove MT, Wallace D: Family systems and deurbanization: Implications for substance abuse, in Lowinson JH, Ruiz P, Millman RB (eds.): Substance Abuse: A Comprehensive Textbook (2nd ed.). Baltimore, MD, Williams and Wilkins, 1992, pp. 944-955.

3. Willms D, Singer SM, Adrien A, Godin G, Maticka-Tyndale E, Cappon P: Participatory aspects of the qualitative research design of Phase II of the ethnocultural communities facing AIDS study. Can J Public Health 87(suppl. 1):S15-S25, 1996.

4. Singer SM, Willms DG, Adrien A, Baxter J, Brabazon C, Leaune V, Godin G, Maticka-Tyndale E, Cappon P: Many voices-Sociocultural results of the ethnocultural communities facing AIDS study in Canada. Can J Public Health 87(suppl. 1):S26-S32, 1996.

5. Cappon P, Adrien A, Godin G, Singer SM, Maticka-Tyndale E, Willms DG, Daus T: HIV/AIDS in the context of culture: Selection of ethnocultural communities for study in Canada. Can J Public Health 87(suppl. 1):S11-S14, 1996.

6. Galea S, Factor SH, Palermo A-G, Aaron D, Canales E, Vlahov D: Access to resources for substance users in Harlem, New York City: Service provider and client perspectives. Health Educ Behav 29(3):296-311, 2002.

7. Freudenberg N: Case history of the Center for Urban Epidemiologic Studies in New York City. $J$ Urban Health 78(3):508-518, 2001.

8. Schwab MG, Neuhauser L, Margen SM, Syme SL, Ogar D, et al: The Wellness Guide: Towards a new model for community participation in health promotion. Health Promotion Int 7:27-36, 1992.

9. Neuhauser L, Schwab M, Syme SL, Beiver M: Community participation in health promotion: Evaluation of the California Wellness Guide. Health Promotion Int 13:211-221, 1998.

10. Fry C, Dwyer R: For love or money? An exploratory study of why injecting drug users participate in research. Addiction 96(9):1319-1325, 2001.

11. Strauss RP, Sengupta S, Kegeles S, McLellan E, Metzger D, et al: Willingness to volunteer in future preventive HIV vaccine trials: Issues and perspectives from three US communities. $J$ Acquir Immune Defic Syndr 26(1):63-71, 2001.

12. MacQueen KM, Vanicseni S, Kitayaporn D, Lin LS, Bauvirat A, et al: Willingness of injection drug users to participate in an HIV vaccine efficacy trial in Bangkok, Thailand. $J$ Acquir Immune Defic Syndr 21(3):243-251, 1999.

13. Morgan DL: Focus Groups as Qualitative Research (2nd ed.). Newbury Park, Sage, 1990.

14. LeCompte MD, Schensul JJ: Analyzing and Interpreting Ethnographic Data. London, Alta Mira, 1999.

15. Berg B: Qualitative Research Methods for the Social Sciences. Boston, Allyn \& Bacon, 1989.

16. Bureau of the Census. Topologically Integrated Geographic Encoding and Referencing System [Online]. Washington, DC, U.S. Department of Commerce, 1995. Retrieved on October 30, 2000, from http://www.census.gov/geo/www/tiger

17. Reason P: Three approaches to participative inquiry, in Denzin NK, Lincoln YS (eds.): Handbook of Qualitative Research. Thousand Oaks, Sage, 1994, pp. 230-245.

18. Pollack LE: Informational needs of patients hospitalized for bipolar disorder. Psychiatr Serv 46:1191-1194, 1995.

19. Teri L: Training families to provide care: Effects on people with dementia. Int J Geriatr Psychiatry 14:110-116, 1999.

20. Gjerdingen DK, Froberg DG, Fontaine P: The effects of social support on women's health during pregnancy, labor and delivery, and the postpartum period. Fam Med 23:370-375, 1991. 